\title{
1. Why is sustainability science needed?
}

Research over the last two decades has shown that human influences on global life-support systems have reached a magnitude unprecedented in human history (Jerneck et al., 2010). On the one hand, pro-growth economic policies have encouraged rapid accumulation of consumption goods and technological innovations (Komiyama and Takeuchi, 2006; Orecchini et al., 2012). This has resulted in increased human prosperity in many parts of the world, although in a globally disproportionate manner. As already stated in the Brundtland report 25 years ago:

Those looking for success and signs of hope can find many: infant mortality is falling; human life expectancy is increasing; the proportion of the world's adults who can read and write is climbing; the proportion of children starting school is rising; and global food production increases faster than the population grows (WCED, 1987, p. 19).

On the other hand, by depleting the world's stock of natural wealth on a global scale - often irreversibly - the prevailing, and predominant, economic and development models increasingly have detrimental impacts on the well-being of present generations, in particular leading to a broadening ecological crisis and ever widening social disparities. Concomitantly, these models present tremendous risks and challenges for future generations.

To document the most salient features of this global crisis, researchers throughout the world have engaged in vast enterprises of collaborative peer-reviewed research. The results of these mega-science projects for monitoring the multi-dimensional crisis have been most visible in the field of climate change research, in particular with the awarding of the Nobel peace prize in 2007 to the International Panel on Climate Change (IPCC). The latter assessment involved over 1000 scientists, from over 120 countries, and is entirely based on a process of peer-review amongst expert reporting on the latest findings from the various sub-fields of climate change research. Similar initiatives have been undertaken to monitor the biodiversity crisis, natural resources depletion and global pollution, amongst others. As a result of these initiatives, scientists working across disciplines and contexts produced a state-of-the-art of major social and ecological indicators in globally significant reports. The most important of these are the following (Swilling and Annecke, 2012, pp. 27-8): 
1. Ecosystem degradation: the United Nations (UN) Millennium Ecosystem Assessment, compiled by over 1300 scientists from 95 countries and released in 2005, has confirmed for the first time that 60 per cent of the ecosystems upon which human systems depend for their survival are degraded (MEA, 2005).

2. Global warming: the broadly accepted reports of the Intergovernmental Panel on Climate Change (IPCC) confirm that global warming since 1950 is mostly due to the release into the atmosphere of greenhouse gases caused by the burning of fossil fuels and (to a lesser extent) deforestation. If global-averaged temperature increased by more than $2^{\circ} \mathrm{C}$ above the pre-industrial level, it would lead to major ecological and socio-economic changes, most of them for the worse, and the world's poor would experience the most destructive consequences (IPCC, 2007). Current projections for the twenty-first century are an increase in global temperatures between 1.6 and $6.9^{\circ} \mathrm{C}$ (above the pre-industrial level), respectively for the most optimistic and most pessimistic scenario envisioned in the 2007 IPCC report (Synthesis report, p. 45).

3. Oil peak: the 2008 World Energy Outlook published by the International Energy Agency declared the "end of cheap oil" (EIA, 2008). Even the major oil companies now agree that oil prices are going to rise due to more difficult to reach extraction sites, and alternatives must be found sooner rather than later. Oil accounts for over 60 per cent of the global economy's energy needs.

4. Inequality: according to the UN Human Development Report for 1998, 20 per cent of the global population account for 86 per cent of total private consumption expenditure, whereas the poorest 20 per cent account for 1.3 per cent (United Nations Development Program, 1998). In addition, inequality of incomes was higher in most OECD countries in the mid-2000s than in the mid-1980s and the past 5 years saw growing poverty and inequality in two-thirds of OECD countries (OECD, 2011). Alternative, more complete indicators of inequality, integrating quality of life indicators and/or capabilities, show similar trends (see also the discussion in section 1.2 below).

5. Urban poverty: according to the UN-HABITAT report entitled The Challenge of Slums, nearly 1 billion of the 6 billion people who live on the planet live in slums or, put differently, one-third of the world's total urban population (United Nations Centre for Human Settlements, 2003).

6. Food insecurity: the International Assessment of Agricultural Knowledge, Science and Technology for Development (IAASTD, 2009) is the most thorough global assessment of the state of agricultural science and practice that has ever been conducted. According 
to this report, modern, industrial, chemical-intensive agriculture has caused significant ecological degradation which, in turn, will threaten food security in a world in which access to food is already highly unequal and demand is fast outstripping supply. Significantly, this report confirmed that " 23 per cent of all used agricultural land is degraded to some degree" (IAASTD, 2009: ch.1, p. 73).

7. Material flows: according to a 2011 report by the International Resource Panel (http://www.unep.org/resourcepanel), by 2005 the global economy depended on 500 exajoules of energy and 60 billion tonnes of primary resources (biomass, fossil fuels, metals, and industrial and construction minerals), an increase of 36 per cent since 1980 (UNEP, 2011a).

As stated by Swilling and Annecke (2012, p. 28), the above trends "combine to conjure up a picture of a highly unequal urbanized world dependent on rapidly degrading eco-system services, with looming threats triggered by climate change, high oil prices and food insecurities".

The situation is worrisome, in particular because most of the driving forces of environmental change such as economic growth, consumption levels in industrialized economies, the size of the world population, resource use and energy consumption continue to increase (Jaeger, 2011). For example, according to the latest forecast by the United Nations Department of Economic and Social Affairs (2011), the world population is projected to surpass 9 billion by 2050, from approximately 7 billion in late 2011. From a business or industrial perspective, this can be translated into billions of new consumers. Therefore population growth may offer room for market expansion, which could be considered as good news (Orecchini et al., 2012). However, the bad news is that the greater scarcity of resources, mounting economic pressure on the environment, and potentially worsening socio-economic conditions for larger parts of humanity, will necessarily influence the ability of those 9 billion to sustain present consumption lifestyles or to attain the standards of living enjoyed by the most developed and richest countries today (Orecchini et al., 2012). As a matter of fact, over the next 40 years, demand for industrial materials in most sectors is expected to double or triple. Projections of future energy use and emissions based on current technologies show that, without decisive action, these trends will continue (UNEP, 2011b).

The Millennium Ecosystem Assessment provides an appropriate illustration of the interdependence between these driving forces of global change, the global sustainability crisis and its impact on human well-being. On the one hand, the Millennium Assessment has shown in its synthesis report that most of the ecosystem services are declining (Table 1.1). On the other 
Table 1.1 Global status of provisioning, regulating and cultural ecosystem services

\begin{tabular}{|c|c|c|c|}
\hline Service & Subcategory & Status & Notes \\
\hline \multicolumn{4}{|l|}{ Provisioning Services } \\
\hline \multirow[t]{5}{*}{ Foods } & crops & $\uparrow$ & $\begin{array}{l}\text { substantial production } \\
\text { increase }\end{array}$ \\
\hline & livestock & $\uparrow$ & $\begin{array}{l}\text { substantial production } \\
\text { increase }\end{array}$ \\
\hline & $\begin{array}{l}\text { capture } \\
\text { fisheries }\end{array}$ & $\downarrow$ & $\begin{array}{l}\text { declining production due to } \\
\text { overharvest }\end{array}$ \\
\hline & aquaculture & $\uparrow$ & $\begin{array}{l}\text { substantial production } \\
\text { increase }\end{array}$ \\
\hline & wild foods & $\downarrow$ & declining production \\
\hline \multirow[t]{3}{*}{ Fibre } & timber & $+/-$ & $\begin{array}{l}\text { forest loss in some regions, } \\
\text { growth in others }\end{array}$ \\
\hline & $\begin{array}{l}\text { cotton, hemp, } \\
\text { silk }\end{array}$ & $+1-$ & $\begin{array}{l}\text { declining production of some } \\
\text { fibres, growth in others }\end{array}$ \\
\hline & wood fuel & $\downarrow$ & declining production \\
\hline Genetic resources & & $\downarrow$ & $\begin{array}{l}\text { lost through extinction and } \\
\text { crop genetic resource loss }\end{array}$ \\
\hline $\begin{array}{l}\text { Biochemicals, } \\
\text { natural, medicines } \\
\text { pharmaceuticals }\end{array}$ & & $\downarrow$ & $\begin{array}{l}\text { lost through extinction, } \\
\text { overharvest }\end{array}$ \\
\hline Water & fresh water & $\downarrow$ & $\begin{array}{l}\text { unsustainable use for } \\
\text { drinking, industry, and } \\
\text { irrigation; amount of hydro } \\
\text { energy unchanged, but dams } \\
\text { increase ability to use that } \\
\text { energy }\end{array}$ \\
\hline \multicolumn{4}{|l|}{ Regulating Services } \\
\hline Air quality regulation & & $\downarrow$ & $\begin{array}{l}\text { decline in ability of } \\
\text { atmosphere to cleanse itself }\end{array}$ \\
\hline \multirow[t]{2}{*}{ Climate regulation } & global & $\uparrow$ & $\begin{array}{l}\text { net source of carbon } \\
\text { sequestration since } \\
\text { mid-century }\end{array}$ \\
\hline & $\begin{array}{l}\text { regional and } \\
\text { local }\end{array}$ & $\downarrow$ & $\begin{array}{l}\text { preponderance of negative } \\
\text { impacts }\end{array}$ \\
\hline Water regulation & & $+1-$ & $\begin{array}{l}\text { varies depending on ecosystem } \\
\text { change and location }\end{array}$ \\
\hline Erosion regulation & & $\downarrow$ & increased soil degradation \\
\hline $\begin{array}{l}\text { Water purification } \\
\text { and waste treatment }\end{array}$ & & $\downarrow$ & declining water quality \\
\hline Disease regulation & & $+1-$ & $\begin{array}{l}\text { varies depending on ecosystem } \\
\text { change }\end{array}$ \\
\hline Pest regulation & & $\downarrow$ & $\begin{array}{l}\text { natural control degraded } \\
\text { through pesticide use }\end{array}$ \\
\hline
\end{tabular}


Table 1.1 (continued)

\begin{tabular}{|c|c|c|c|}
\hline Service & Subcategory & Status & Notes \\
\hline Pollination & & $\downarrow$ & $\begin{array}{l}\text { apparent global decline in } \\
\text { abundance of pollinators }\end{array}$ \\
\hline $\begin{array}{l}\text { Natural hazard } \\
\text { regulation }\end{array}$ & & $\downarrow$ & $\begin{array}{l}\text { lost of natural buffers } \\
\text { (wetlands, mangroves) }\end{array}$ \\
\hline \multicolumn{4}{|l|}{ Cultural Services } \\
\hline $\begin{array}{l}\text { Spiritual and } \\
\text { religious values }\end{array}$ & & $\downarrow$ & $\begin{array}{l}\text { rapid decline in sacred groves } \\
\text { and species }\end{array}$ \\
\hline Aesthetic values & & $\downarrow$ & $\begin{array}{l}\text { decline in quantity and quality } \\
\text { of natural lands }\end{array}$ \\
\hline $\begin{array}{l}\text { Recreation and } \\
\text { ecotourism }\end{array}$ & & $+1-$ & $\begin{array}{l}\text { more areas accessible but } \\
\text { many degraded }\end{array}$ \\
\hline
\end{tabular}

Notes: The "substantial production increase" in crops is achieved at the expense of a $5 \%$ annual increase in the application of chemical fertilizers; the "substantial production increase" in aquaculture is achieved at the expense of permanent damage to capture fisheries; the "substantial production increase" in livestock is achieved at the expense of degraded environment, increased use of antibiotics and hormones, use of chicken manure as feed and expanding feedlots industry.

Source: MEA (2005, p.7).

hand, as will be discussed in more detail in Chapter 3, the evolution of these ecosystem services has a negative impact on physical, emotional and social well-being, leading to a call for change in governance and economic and social policy (see in particular Figure 3.1). More recently, a quantitative assessment of the threshold levels of the critical global-scale processes, published in Nature, has shown that for nearly all the critical processes the observed values are close to or already exceeding the critical thresholds (Rockström et al., 2009, cf. also the discussion in section 3.4.2 below).

This brief overview shows that, despite international agreements and action plans at all levels, there has been no success over the past few decades in reconciling human development with the environmental limits of the earth and in securing well-being for all people on this planet now and in the future (Jaeger, 2011). Indeed, we are faced with persistent problems of non-sustainability resulting from overexploitation of the planet's resources and from surpassing the threshold of its capacity to assimilate wastes. Transformative research is needed so that sustainable pathways can be explored and taken (Jaeger, 2011).

The following sections focus on three hard problems for transformative research that follow from this situation of non-sustainability and whose solution should be at the core of the principles of the emerging field of 
sustainable science: first, the problem of non-substitutability of natural capital by produced/technological capital; second, the problem of mounting inequalities; and, third, the need to bridge the gap between science and society.

\subsection{THE CHALLENGE OF DECOUPLING GROWTH FROM THE EXPLOITATION OF NATURAL RESOURCES}

During the last two centuries, the scale of human activities has grown exponentially. This growth has led to a situation where human social systems and the earth's ecological systems have become strongly coupled systems which have to be addressed in an integrated manner (Costanza et al., 1993). In particular, scientists and policy makers have recognized the need to acknowledge the biophysical constraints on the future possibilities of development of human societies. Such biophysical constraints include: (1) the provision of raw materials for direct consumption and production; (2) the limits on the capacity for assimilation of waste products by the earth's ecosystems; (3) the maintenance of the provision of landscape, information and cultural services by ecosystems; and (4) the maintenance of the provision of basic life-support functions that are prerequisites of all of the above (Ekins et al., 2003).

Sustainability in the context of the analysis of social-ecological systems can be described as the "maintenance of different types of essential capital" (Goodland and Daly, 1996). In the case of economic sustainability it refers mainly to financial capital. For example, historically, at least as early as the Middle Ages, merchants wanted to know how much of their sales receipts could be consumed by their families without depleting the capital of their business (for example by using only the net profits, minus investment costs, for their private consumption). More recently, the concept of sustainability is increasingly used in the context of the ecological crisis, where the term "environmental sustainability" refers to the maintenance of natural capital.

Sustainable development aims at an equitable use of the different types of capital that are essential for the functioning of coupled social-ecological systems. In general the different types of capital can be subdivided into natural capital on the one hand and different forms of human capital on the other (composed of cultural capital, institutional capital, social capital and technological/produced capital). In this context, different approaches to sustainability have been proposed according to the possibility of substituting natural with technologicallproduced capital (technological artefacts and products of labour), ranging from weak sustainability (complete 


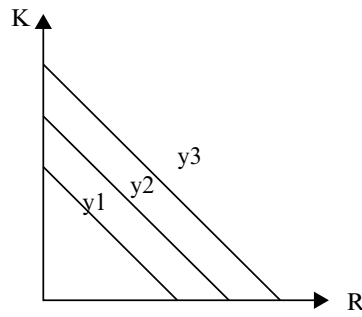

(a)

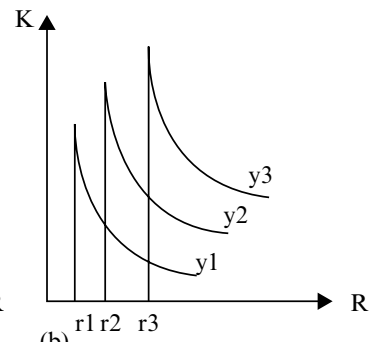

(b)

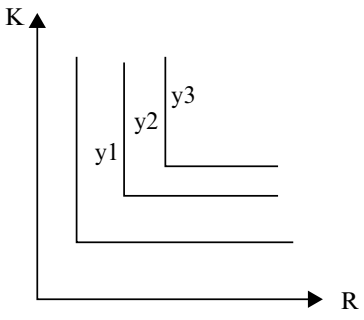

(c)

Note: The three types of production functions link constant national income $y_{i}$ with technological/produced capital stock $K$ (such as technology) and amount of natural capital $R$ (such as non-renewable natural resources), under (a) full substitutability between $K$ and $R$ (= weak sustainability approach); (b) limited substitutability between $K$ and $R$ (= strong sustainability approach); and (c) no substitutability (= limit case of strong sustainability).

Source: Adapted from Common and Stagl (2005, p. 220).

Figure 1.1 Different types of production functions

substitutability of natural by technological/produced capital) to different forms of strong sustainability (limited or no substitutability of natural by technological/produced capital).

Figure 1.1 illustrates the different degrees of substitutability between natural resources $(R)$ and technological/produced capital $(K)$. Case (a) assumes full substitutability between natural resources and capital $K$, allowing a complete replacement of natural resources by capital $K$ (weak sustainability). The second production function (b) corresponds to the existence of a limit on the substitution possibilities, with the recognition of a necessary minimum threshold of available natural resources in any production processes (represented by the minimum threshold levels $r 1, r 2, r 3$ for each production function) (strong sustainability). The last graphic (c) represents a production function where no substitution is admitted (which is a limit case of strong sustainability).

\subsubsection{Weak Sustainability Compared to Strong Sustainability}

The weak sustainability approach (scenario (a) in Figure 1.1) extends the neoclassical model of economic development and considers nonrenewable natural resources as one of the factors of production, seeking to "establish rules on how much natural resources to consume now and how much to invest in produced/technological capital to increase consumption later, when the non-renewable resources will be exhausted" (Dietz and Neumayer, 2007). This approach assumes that utility obtained from natural 
capital and technological/produced capital is substitutable. For example, if individual utility is measured by individual monetary income, replacing wood products by plastic, or a natural floodplain by a dyke built in stone, does not make any difference from a weak sustainable perspective if such substitution leads to an equivalent level of goods and individual income (after taxation/after buying the consumption goods). In both these cases of substitution, neither the intrinsic limit of earth's resources, nor the value of certain natural resources for the appropriate functioning of basic ecosystems is taken into account. In fact, the weak sustainability model requires that (a) natural resources are super-abundant; (b) the elasticity of substitution between natural and produced capital is greater than or equal to unity (that is: the marginal gain in utility is greater or equal than unity when substituting natural capital $R$ by technological/produced capital $K$ as input in the production process); or (c) technological progress can increase the productivity of the natural capital stock faster than it is being depleted.

The weak substitutability approach leads to a development policy focused on the exploitation of natural resources in a way that allows a sustainable income stream from natural resources to be retained from new human capital investments, in spite of the depletion of the natural resources. This logic can be illustrated, for example, by the permanent process of compensation of loss of soil fertility, consequent to intensive agricultural practices, through increasing the recourse to mechanization, irrigation and fertilizers (Krishnan et al., 1995, p. 98). However, often the technological substitutes rely themselves on non-renewable natural resources (such as oil and fresh water in the case of fertilizers and irrigation). In such cases, the weak sustainability approach clearly is only a short-term relief based on the promises of technological progress without disposing of a well-established long-term road map.

Conversely, the strong sustainability approach acknowledges that not all the functions of natural capital can be replaced by produced/technological capital and that there are critical levels beyond which substitutability is no longer possible (Daly and Farley, 2011). Situations of non-substitutability arise, for example, when critical thresholds are reached for the assimilation of waste products (such as greenhouse gases in the atmosphere) or for the functionality of living systems (such as the collapse of a fishery's ecosystem). As Daly and Farley (2011, p. 161) put it, complete substitutability would signify that a cooker can make a $1000 \mathrm{lb}$ cake, using just the ingredients required for a $5 \mathrm{lb}$ cake, "by stirring harder and baking longer in a bigger oven" (in Figure 1.1(b), this would mean to produce income level $y 3$ by using the same level of natural resources as income level $y 1$, which is clearly not possible in all situations, as $y 3$ can only be produced if resources are available at minimally the critical threshold $r 3$ ). 
From a policy perspective, the criterion of strong sustainability has been used for example in the IPCC report. The IPCC's $450 \mathrm{ppm}$ stabilization target has been calculated based on a maximum tolerable increase of global temperatures of between 2 and $3^{\circ} \mathrm{C}$. Beyond this temperature increase, the evolution of the climate would potentially reach threshold effects that cannot be compensated any more by technological means. In further developments of the strong sustainability approach, additional attention is drawn to the fact that those critical levels for substitutability are extremely difficult to assess. As argued initially by Holling (1973), when threshold levels are difficult to assess, a more responsible approach should focus on preserving the functionality of living systems over time (resilience) and on maintaining each type of capital (natural, cultural, institutional, social and produced/technological) intact independently (Common and Stagl, 2005; Goodland and Daly, 1996).

Finally, scenario (c) in Figure 1.1. corresponds to a view where no substitution is permitted, that is no natural resource can ever be depleted. This view seems to be unnecessary as resilience is not necessarily achieved only through a static vision of nature, but can be achieved by a dynamic, but sustainable, co-evolution of the natural environment and human societies. This scenario has been labelled by some as absurdly strong sustainability (Goodland and Daly, 1996). However, even though a universal application of scenario (c) can rightly be labelled absurd, this scenario still might be very relevant for some of the basic features that determine the health of critical ecosystem services on earth. In particular, this scenario could apply to situations where the exhaustion of natural resources or environmental degradation beyond a certain threshold would lead to so-called "tipping points" of irreversible damage to these basic services. One such case that has been recently documented in a review paper in Nature is the existence of planetary-scale tipping points, beyond which the earth's ability to sustain us and other species would be threatened (Barnosky et al., 2012).

\subsubsection{Beyond Eco-efficiency: The Challenge of Absolute Decoupling}

The weak sustainability approach, currently dominating current mainstream economics, is based on the assumption that economic growth can be decoupled from material throughput through decrease of natural resource use in production systems, in particular by technical innovation. Such decoupling is supposed to cover both a decrease in consumption of non-renewable resources and a decrease of the production of waste products that have to be assimilated by the earth's ecosystems. In particular, the weak sustainability approach assumes that technological innovation, together with behavioural changes towards more sustainable consumption 


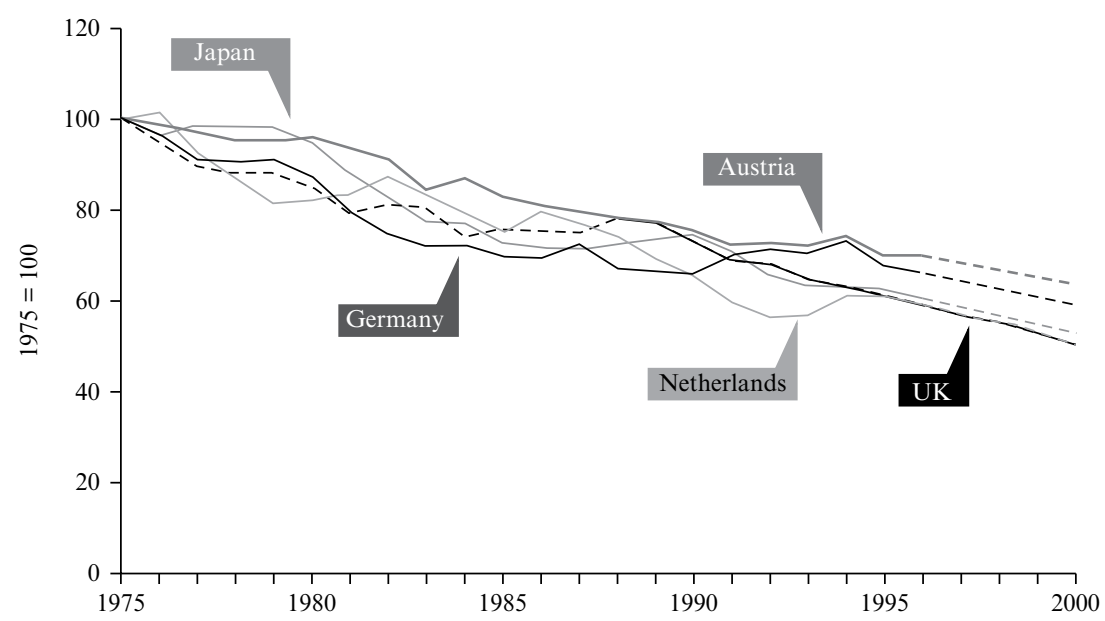

Notes: The relative decoupling is measured as direct material consumption (DMC) per unit of GDP, indexed to 1975 . Figure based on rough estimates - more accurate use of the statistical data, however, reveals similar trends for relative decoupling (see Laurent, 2011). The indicator that is used (DMC) measures the total amount of materials directly used in the economy, minus the materials that are exported. The DMC indicator does not include the outsourcing of "dirty" production/extraction to other countries. The use of the Total Material Consumption (TMC), which includes such outsourcing, would be more accurate, but is difficult to measure with the current data (Eurostat, 2001). The latter gives in any case a less optimistic scenario and would be likely to lead to the absence of relative decoupling, that is no decrease in TMC per unit of GDP (see Laurent, 2011).

Source: Jackson (2009, p. 49).

Figure 1.2 Relative decoupling in OECD countries: 1975-2000

patterns, will ensure that continuing growth of consumption is compatible with a sufficient level of environmental protection. But evidence of decoupling of economic growth from depletion of natural capital shows mixed results at best. Granted, the last three decades have witnessed a marked increase in relative decoupling, that is a decrease in use of natural capital per unit of economic output (for example measured in terms of GDP), in part as a consequence of increased eco-efficiency (a more efficient use of resources or a reduction in pollution intensity per unit of economic output). To illustrate this trend, Figure 1.2 presents the increasing levels of energy efficiency for five developed countries. A second illustration of this trend is the decrease in carbon emission efficiency in most developing nations during the 1990s. However, since 2000, these gains are likely to be totally offset by a new wave of use of inefficient carbon technologies in these developing nations (Jackson, 2009, p. 49). 


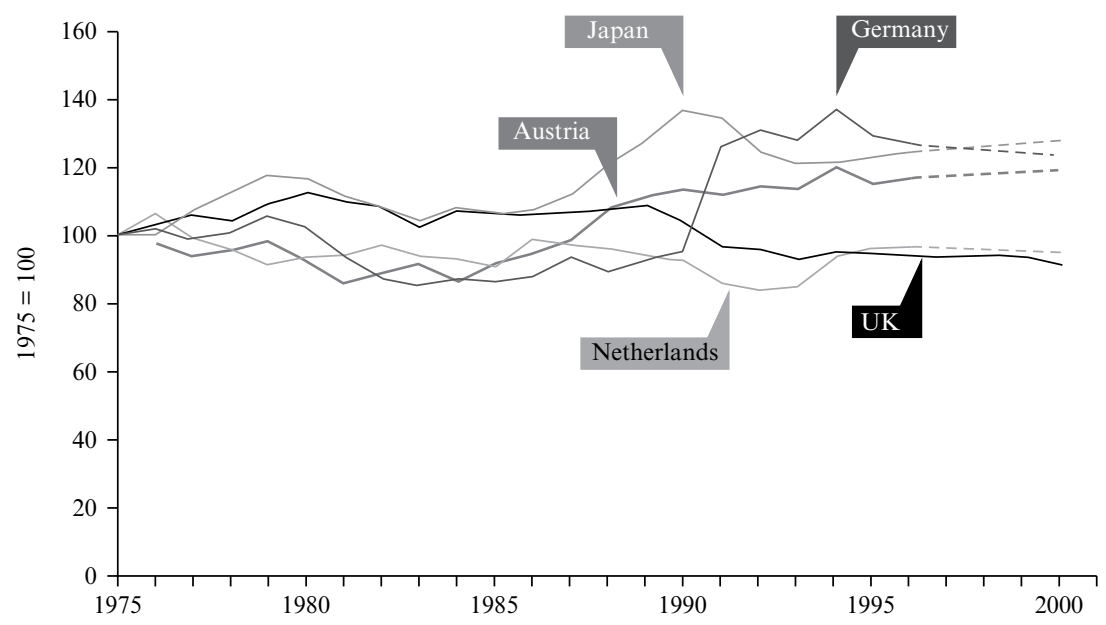

Notes: Different use of the statistical data, however, seems to reveal an absolute decoupling for European countries - as one of the few regions in the world - if one does not take into account the outsourcing of "dirty" production/extraction to other countries (Laurent, 2011). Using the Total Material Consumption (TMC) (see note to Figure 1.2) would again lead to no absolute decoupling, even for Europe (Laurent, 2011).

Source: Jackson (2009, p. 51).

Figure 1.3 Direct Material Consumption (DMC) in some OECD countries: 1975-2000

Relative decoupling is certainly a necessary condition for ecological sustainability. But it is not a sufficient condition. First, even in relative terms, the global trend of increased efficiency hides significant differences between developed and developing countries. Second, what matters for ecological sustainability is absolute decoupling, that is an absolute reduction of the increase of the use of natural resources. But relative decoupling has not led to such absolute decoupling on the global scale. Rather, global energy consumption in absolute terms has continued to increase in the period 1975-2000. For example, according to estimations of Tim Jackson, even though relative efficiency of energy use increased in the OECD, with overall energy efficiency gain of up to 50 per cent in some countries, absolute energy consumption also increased or stayed at the same level in these countries (Jackson, 2009, p. 51; see Figure 1.3). Other estimations seem, however, to indicate the possibility to realize a certain level of absolute decoupling for certain countries in Europe for the use of certain resources within the EU. For example, according to the available data from the GIEC report, overall greenhouse gas emission remained more or less stable 


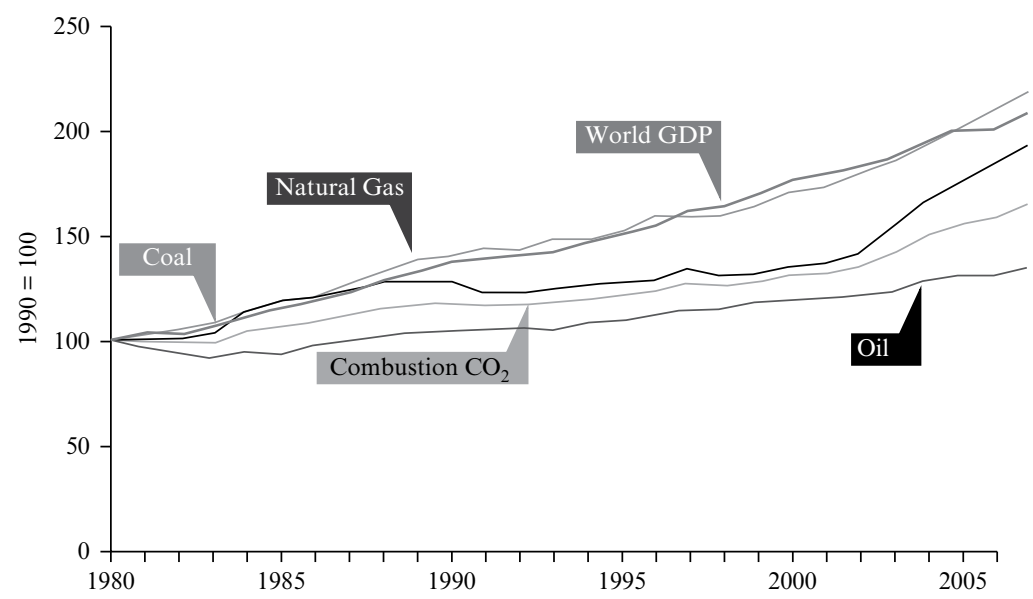

Source: Jackson (2009, p. 50).

Figure 1.4 Trends in fossil fuel consumption and related CO2 emissions: 1980-2007

in the EU over the period 1996-2007, while real GDP increased by 30 per cent (Laurent, 2011). However, overall use of natural resources and accumulation of waste products resulting from EU consumption continued to increase over the same period, if one includes the environmental impact of the delocalization of production sites for EU consumption products to non-EU countries. Therefore, the real impact of economic growth in the EU on greenhouse gas emission is much higher and the available evidence does not confirm the absolute decoupling when measured by the Total Material Consumption in the EU (Laurent, 2011).

As a result of these trends, even if carbon emissions from fossil fuels have increased more slowly than the increase in economic activity, in 2007 they were still 80 per cent higher than in 1970 and 40 per cent higher than in 1990, the reference year of the Kyoto Protocol (IPCC, 2007, see also Figure 1.4). This is especially alarming knowing that to meet the IPCC's 450 ppm stabilization target mentioned above, global carbon emissions would have to decrease by $50-85$ per cent by 2050 .

For absolute decoupling to occur under the present market economy that is oriented towards growth in GDP, the rate of eco-efficiency improvement must be large enough annually to offset the combined impact of growth in population and growth in average income spent on new consumption goods (Weaver, 2011), whether from own production or from import. In addition the eco-efficiency gain must be "captured" and "dedicated" 
to reducing the absolute use of resources by the global economy, rather than being redeployed to support further material growth. Yet the market is structured and oriented in a way that ensures that gains in efficiency are dedicated to further growth through expanding consumer demand, without factoring in the intrinsic limits of this growth related to the critical thresholds of natural capital.

Under present global market arrangements, investment in research and development to accelerate eco-efficiency is therefore unlikely to translate into absolute decoupling (Weaver, 2011). Moreover, as is well known, energy efficiency gains can paradoxically also result in increases in energy use, or lead to less than expected environmental gains through the so-called rebound effect (Saunders, 1992). For example, a 5 per cent improvement in vehicle fuel efficiency might result only in a 2 per cent drop in fuel use, because the increased efficiency encourages drivers to go faster or further than before. Therefore, there is no reason (or credible evidence) to expect that appeals to conventional political and business logic based on improving eco-efficiency under the current development model will solve the problem of resource scarcity. This points to the need to go beyond the weak sustainability approach and to revise the broadly conventional role of scientific work in support of sustainable development, focused all too often only on undertaking research into resource substitution by technology, increasing energy productivity and reducing emissions of wastes and pollution (Saunders, 1992). These implications for scientific research, in an approach which recognizes the need to focus on absolute decoupling, will be further discussed in Chapter 3.

\subsection{THE CHALLENGE OF SOCIAL EQUITY FOR SUSTAINABLE DEVELOPMENT}

An uneven distribution of wealth worldwide has resulted from resourceextractive, industrial pro-growth development, as the limits to the earth's resources necessarily influence the ability of the estimated 7 billion human beings to benefit from this wealth. A World Bank survey of 1999 showed that the ratio between the average income of the top 5 per cent in the world to the bottom 5 per cent increased from 78 to 1 in 1988 to 114 to 1 in 1993 (Milanovic, 2002). New evidence on changes in poverty and income in the OECD countries shows a similar trend in the industrialized countries over the last 25 years. Inequality of incomes was higher in most OECD countries in the mid-2000s than in the mid-1980s and the past 5 years saw growing poverty and inequality in two-thirds of OECD countries (OECD, 2011). In particular, even traditionally low inequality countries 
such as Japan, Sweden and Denmark are experiencing growing inequality. In Japan and Israel, the lower classes' average annual income actually fell. However, some countries bucked the trend: France, Spain and Greece (before the 2008 financial crisis) have moved towards greater equality of incomes over the past 20 years, and both Mexico and the United Kingdom have seen a shrinking gap between rich and poor since 2000 . This proves that there is nothing inevitable about the trend towards increased income inequality.

These statistics on equality are of course a very gross approximation and only indicate some trends that have to be further analysed. In particular, the use of income inequality as a measure of social inequality is of very poor relevance if we want to analyse the relationship between inequality and sustainable development. In this context, it is sufficient to recall that the social security safety nets vary from one country to another. As a result, a similar level of income inequality will have a different impact on human well-being in different countries. Therefore, as will be argued below, any useful comparison of levels of inequality should start from alternative indicators that integrate broader evaluations of human development, such as quality of life and/or capabilities (see section 3.2.2). However, in the present state of affairs, such alternative methodologies are still under development (Schiellerup et al., 2009). In any case, the call for using alternative methodologies only reinforces the point that social inequality is closely related to broader dimensions of human development.

Global and country inequality is also a central issue for reaching the transition towards strong sustainability. First, the impacts of environmental decline are felt disproportionately by the poor in developing countries (Srinivasan et al., 2008; WCED, 1987). Indeed, developed countries delay and relocate damaging effects, such as hazardous technologies and polluting industries (Andersson and Lindroth, 2001), to poorer nations while continuing to consume high volumes of material and energy from these same countries. In addition, rising poverty and unemployment have increased pressure on environmental resources as more people have been forced to rely more directly upon them. For instance, in many African countries, low quality of life, and lack of energy and livelihood choices have driven ecosystem decline and the migration of underprivileged and disenfranchised populations (Van der Leeuw et al., 2012). Second, although the challenges and scope of these impacts are less dramatic in industrialized countries, similar patterns of higher impact of environmental degradation for vulnerable populations have been observed there. For example, recent research into environmental justice in industrial countries has found that poor and minority neighbourhoods are more likely to contain commercial 
hazardous-waste facilities, sources of toxic pollutants, and sources of air and water pollution (Baland et al., 2006; Ringquist, 2004; Boyce, 2007).

Disparities of wealth, and related disparities of power, influence not only how the pie of natural resources is sliced, but also the overall magnitude of the use of the natural resources (Baland et al., 2006). The main reason is that, without social equity, a society cannot build a social base for conservation of its natural resources (Shiva, 2011). These resources are commons, and it is only when society has organized a fair and equitable use of the ecosystem services provided by these resources that a common concern and action for these resources can be expected. When social and power disparities are great, those at the top of the political and economic ladder can more easily pollute the air and water, and deplete the natural resource base, of those at the bottom, in particular because the elites in those countries have the ability to pay for avoiding the negative impact of resource degradation. In addition, when disparities are small, those on the bottom rungs of the shorter ladder are better able to defend themselves. A democratic distribution of power and equitable distribution of wealth, therefore, can help to protect the environment. Conversely, an oligarchic distribution of power and an inequitable distribution of wealth can exacerbate environmental degradation. A striking illustration of the latter is the massive export of tropical hardwoods in the Philippines during the Marcos regime in the 1960s and 1970s. Those who benefited most from the logging industry were well-connected politicians and military officers, and those who suffered most from its consequences were poor people who lived in or near the forest.

In spite of the overall negative trends in relation to social equity, many actors at all scales have started to develop initiatives to address the joint problems of social inequality and environmental degradation. In particular, a combination of government economic incentive schemes, local community organizations and science-based decision support systems has proven to be a very effective tool in many situations around the world. For example, in the Rio Platano Biosphere Reserve in Honduras, communities have been able to overcome the poverty-driven degradation of shared ecosystems by agreeing upon alternative ways of exploiting them and reorienting the local economy towards non-timber forest products (such as cocoa, ornamental plants, medicines and oil), based on the use of traditional knowledge and a community-based governance model (Weaver, 2011). In another case, in Flanders, Belgium, small-scale forest owners with few resources were able to self-organize in forest groups in the mid-1990s to address the serious ecological degradation of the pine forests planted in the mining regions. These groups combined common ecological management of the forest and selling of firewood with the rebuilding of 
social capital and social learning around the new sustainability challenges (Dedeurwaerdere, 2009).

The interdependence between environmental degradation, social equity and poverty has been highlighted in many reports and analyses, particularly since the end of the 1980 s when it came to the fore of the world's attention with the publication of the Brundtland report (WCED, 1987). Sustainability science, with its focus on complex social-ecological interactions and the participatory organization of research, seems especially well placed to tackle these issues and help to design appropriate policy mechanisms. However, at present such integrated social-ecological approaches to social inequality are still very marginal (with some notable exceptions, for example the body of research presented by Baland et al., 2006) and have received very little attention from mainstream projects on sustainable development. Traditional approaches all too often treat the external costs of environmental degradation as impersonal by-products of economic activities, without scrutinizing the social dynamics that lead to the maintenance of these externalities in the first place. On the other hand, environmental policies can also lead to increasing social inequalities when these policies are applied without due consideration of the social impacts. A case in point is the carbon emissions trading scheme in Europe, the cost of which is in large part paid by the consumers, through increasing energy prices. Better synergies with social policies, such as targeted support for vulnerable households or low-income groups should be part of the appropriate policy mix in order to mitigate these social consequences. Therefore, without a more fine-grained social, economic and ecological analysis of such synergies, and a broader involvement of the stakeholders in the elaboration of solutions, it is highly unlikely that the conventional financial policy tools of taxes, fines or market creation, which are only based on the calculus of internalization of environmental externalities into market prices, will be able to drive societies' transition towards a long-term sustainable development path.

\subsection{BRIDGING THE GAP BETWEEN SCIENCE AND SOCIETY}

Scientific and political interest in the degradation of the environmental commons grew throughout the 1970s largely in reaction to frightening news stories about sharp population declines in many species, acid rain and deforestation in the tropics. This interest appeared at a time when major environmental works such as The Population Bomb (Ehrlich, 1968), The Limits to Growth (Meadows et al., 1972) and Garrett Hardin's paper "The 
tragedy of the commons" (1968) were at the forefront of the academic and policy debates. These works all pointed to similar conclusions: that the global environment was threatened by what seem to be very fundamental attributes of the human being (Stern, 2011): for Ehrlich our desire to procreate; for Meadows, our tendency to endlessly expand the production and consumption of goods and services; and for Hardin our short-sightedness and tendency to put ourselves first. These works inspired in turn a generation of environmental regulations, by which central governments sought to "command and control" human appetites, through the conventional policy tools of direct regulation, incentive politics and market creation. However, in spite of important and substantial progress in specific fields (such as combating acid rain and river pollution, and an increase in protected areas in industrialized countries), most of the policies were based on overly simplified models and simple "cure-all" solutions. As a result, there has been no overall transition to a more sustainable development path (Stern, 2011).

Hardin's vision in particular was very influential. His solution to the crisis was "mutually agreed upon coercion". However this involved a twofold oversimplification (Dietz et al., 2003): Hardin claimed that only two institutional arrangements - centralized government for some problems and further privatization of property for the other problems - could sustain the commons in the long run; and he presumed that resource users were trapped in a commons dilemma, unable to create solutions. He missed the point that many social groups have struggled successfully against threats of resource degradation by developing and maintaining self-governing institutions in communities and social networks. Moreover, he assumed that only coercive rules or market incentives can be effective for governing the commons, and did not consider social norms or personal values in favour of common goods as valid drivers of sustainable governance frameworks. Although institutions based on local decentralized government or non-state collective action have not always succeeded, neither have Hardin's preferred alternatives of private or state ownership.

The main problem with these early initiatives is not that environmental regulation is inappropriate, but that it has been advocated as a "cure-all" solution or a panacea without envisaging a more interactive and participative process between scientists, policy makers and stakeholders. Especially, in the 1980s and 1990s, with the influential turn towards neo-liberal market deregulation initiated under the Reagan administration in the USA, market-based solutions have been treated as panaceas. For example, it is astonishing that market-based tools (such as tradable marketable pollution permits in agriculture, carbon emission certificates under the Kyoto Protocol, and tradable permits for fishing in EU policy) continue to be presented as the optimal method for solving free-rider problems and for 
providing effective common-pool resource management (Pearce et al., 1989). Tradable market permits, like all institutional arrangements, have notable limitations (Dietz et al., 2003). They tend to leave unprotected the vast set of resources that are not specifically covered by trading rules (for example by-catch of fish species not covered by the permit) and they are ineffective when monitoring is difficult (for example under the Kyoto Protocol, the issue about whether geologically sequestered carbon will remain sequestered is difficult to monitor). Problems can also occur with the initial allocation of allowances, especially when historic users, who may be called on to change their behaviour most, have disproportionate power over allocation decisions or over local governments that fail to enforce their obligations to pay into the scheme (as happened with Arcelor-Mittal in Wallonia, Belgium, which called upon the local government to pay the tradable pollution permits). Similar panacea thinking has led to the promotion of governmental ownership in all situations (such as the idea that protected areas are the only solution to tackling biodiversity decline) or to portraying collaborative approaches through community participation as a "cure-all" (to the distress of researchers who work in the field) (Ostrom et al., 2007).

In spite of the fact that panacea thinking has led to poor environmental policy, it remains deeply embedded in the current scientific practice of giving expert advice to governments. This is especially true because of the dominance of the formal hypothetic-deductive epistemological model of the biophysical sciences, leading to so-called value-neutral statements that can be readily used for policy advice, in spite of the many failures of this model to deal with complex coupled social-ecological systems, at multiple scales and in conditions of strong uncertainty. Instead of adopting a simple class of formal models, for example through reducing individual behaviour to a simple model of self-interested utility maximizers, closer attention to the diversity of institutional histories and set of behavioural motivations is required (as has been advocated by sustainability scholars such as Ostrom (2007) and Young (2002) over the last twenty years). This will, however, in turn require the development of a more interdisciplinary, iterative and open-ended organization of the interaction between science and policy makers, in close collaboration with social actors and practitioners who can contribute to problem framing and ongoing assessment and revision of proposed solutions. 